\title{
A FORMAÇÃO DO ENFERMEIRO PARA O CUIDADO NA ATENÇÃO BÁSICAÀ SAÚDE
}

\author{
Elisabete Takeda* \\ Márcia Padovan Otani** \\ Kátia Alves Rezende*** \\ Mara Quaglio Chirelli**** \\ Sílvia Franco da Rocha Tonhom***** \\ Cássia Regina Rodrigues Nunes ${ }^{\star \star \star * \star \star}$
}

\section{Resumo}

O presente trabalho pretende relatar a experiência desenvolvida durante o ano de 2002, na $1^{\text {a }}$ série do Curso de Enfermagem da Faculdade de Medicina de Marília (FAMEMA). A partir de 1998 iniciou-se um novo Projeto Político-Pedagógico (PPP) que tem como objetivo formar um profissional generalista, crítico e reflexivo, capaz de trabalhar em equipe, promovendo cuidados de enfermagem de forma humanizada. Adotou-se como estratégias para implementação do PPP o currículo integrado e a Metodologia da Problematização, articulando a formação ao mundo do trabalho. Dentre as competências a serem desenvolvidas para atuarem na atenção básica à saúde, utilizou-se como estratégia a integração entre $1^{\mathrm{a}}$ e $2^{\mathrm{a}}$ séries em uma microárea, aplicando a técnica do MAPP.

Descritores: educação; educação em enfermagem; currículo; atenção básica à saúde

\section{Abstract}

This work aims at describing the experience of the $1^{\text {st }}$ grade class in the Nursing Course at the Faculty of Medicine of Marilia (FAMEMA) in 2002. In 1998, a new Political-Pedagogical Project (PPP) was started aiming at educating a critical and reflexive professional, capable of teamwork, by promoting nursing care in a humane way. An integrated curriculum and the problematisation methodology were adopted as strategies to implement the PPP, tailoring education to the job market. Among the competencies to be developed toward basic health care, they employed a strategy to integrate $1^{\text {st }}$ and $2^{\text {nd }}$ grade classes in a microarea by applying the MAPP technique. Descriptors: education; nursing education; curriculum; basic health care

Title: Educating a nurse for basic health care

\begin{abstract}
Resumen
El presente trabajo pretende relatar la experiencia desarrollada durante el 2002, en la $1^{a}$ serie del Curso de Enfermería de la Facultad de Medicina de Marília. En 1998 empezó un nuevo Proyecto Político-Pedagógico $(P P P)$ que tiene como objetivo formar un profesional generalista, crítico y reflexivo, capaz de trabajar en equipo y promover cuidados de enfermería de forma humanizada. Se adoptó como estrategia para implementar el PPP el currículo integrado y la Metodología de la Problematización, articulando la formación al mundo del trabajo. Entre las competencias que se deben desarrollar para que el enfermero actúe en la atención básica a la salud, se utilizó hacer una integración entre la $1^{a}$ y la $2^{a}$ series en una micro área, aplicando la técnica del MAPP.
\end{abstract}

Descriptores: educación; educación en enfermería; currículo; atención básica a la salud

Titulo: La formación del enfermero para el cuidado en la atención básica a la salud

\section{Inrodução}

A formação da força de trabalho em saúde tem sido tema de discussão e propostas em vários fóruns. O Projeto UNI (Uma Nova Iniciativa na educação dos profissionais da saúde: união com a comunidade), financiado pela Fundação Kellogg, constitui-se em uma das iniciativas de mudança da atenção à saúde e da capacitação dos profissionais desta área através de um processo pautado na parceria entre a universidade, os serviços de saúde e a comunidade(1).

A Faculdade de Medicina de Marília (FAMEMA) fez parte deste projeto, envolvendo os cursos de enfermagem e medicina, tendo iniciado suas atividades no ano de 1992. No Curso de Enfermagem foram desenvolvidas diversas atividades que proporcionaram a reflexão e mudanças gradativas na grade curricular e na metodologia de ensino-aprendizagem em algumas disciplinas.

As experiências introduzidas contribuíram para a elaboração do novo Projeto Político-Pedagógico (PPP), o qual pretende formar um profissional generalista, crítico e reflexivo, capaz de trabalhar em equipe, tomar decisões e intervir no processo saúde-doença, considerando o perfil epidemiológico local e promovendo cuidados de enfermagem de forma humanizada tendo como responsabilidade a atualização constante de suas competências.
Dessa forma, o PPP visa a integração entre teoria e prática, ou seja, articular a formação dos profissionais ao mundo do trabalho e à comunidade, através do currículo integrado e da Metodologia da Problematização, tendo iniciado a sua implementação em 1998(2).

Ao tomarmos como desafio a formação crítico-reflexiva, optamos pela Metodologia da Problematização na qual o aluno é o construtor do seu conhecimento de forma ativa, refletindo sobre as práticas desenvolvidas na realidade em que está inserido, buscando construir uma visão crítica de forma consciente e reflexiva.

Assim,

o homem pode refletir sobre si mesmo e colocar-se em um determinado momento, numa certa realidade: é um ser na busca constante de ser mais e, como pode fazer esta auto-reflexão, pode descobrir-se como um ser inacabado, que está em constante busca. Eis aqui a raiz da educação(3:27).

Outro eixo do PPP é a articulação da formação ao mundo do trabalho, considerando a construção da visão crítica do profissional, por isso optamos pelo modelo curricular integrado. Entendemos por currículo integrado a organização dos conteúdos de forma interdisciplinar e que a metodologia de ensino proposta seja baseada na investigação cooperativa,

\footnotetext{
* Enfermeira. Doutora em Enfermagem Fundamental. Docente da disciplina Enfermagem Clínica do Curso de Enfermagem da FAMEMA. **Enfermeira. Mestre em Enfermagem Psiquiátrica e Saúde Mental. Docente da disciplina Enfermagem Psiquiátrica/Saúde Mental do Curso de Enfermagem da FAMEMA. ***Enfermeira. Mestre em Enfermagem em Saúde Coletiva. Docente da disciplina Enfermagem em Saúde Coletiva do Curso de Enfermagem

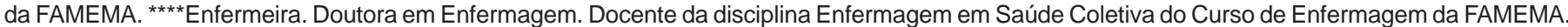

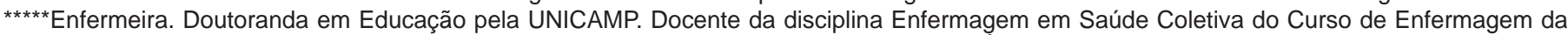
FAMEMA. ******Enfermeira. Mestre em Enfermagem Fundamental. Docente da disciplina de Ética e Bioética do Curso de Enfermagem da FAMEMA. E-mail do autor: etakeda@terra.com.br
} 
conectando o currículo escolar à realidade, devendo ficar explícita para os alunos a relação entre os conteúdos que as instituições escolares trabalham e sua validade para a compreensão e intervenção na sociedade(4).

A promessa inerente ao modelo curricular integrado é a busca de conectar o aluno à vida cotidiana, no caso os serviços de saúde e a comunidade, e a partir das experiências vividas num determinado cenário de ensino-aprendizagem procurar entender e ampliar, através de sucessivas aproximações, a compreensão sobre o que está ocorrendo, articulando as diversas áreas do conhecimento na perspectiva da interdisciplinaridade e, o que ele pode fazer com os problemas e as necessidades de saúde identificadas, como pode intervir numa dada realidade enquanto profissional da enfermagem ${ }^{(5)}$.

Considerando o exposto acima, o novo currículo do Curso de Enfermagem está organizado em séries e em unidades educacionais, distribuídas em 4 anos, com carga horária total de 4240 horas. No primeiro e segundo anos abordamos a assistência de enfermagem sistematizada ao indivíduo, família e comunidade com enfoque na vigilância à saúde, no nível de atenção básica à saúde; na $3^{a}$ série abordamos o cuidado de enfermagem sistematizado ao indivíduo hospitalizado em situações clínico-cirúrgicas e obstétricas, considerando a inserção na família e na sociedade, as políticas públicas e a organização hospitalar e na $4^{a}$ série a realização da assistência de enfermagem nos diversos níveis de atenção, atuando em equipe multiprofissional com enfoque interdisciplinar, com ações voltadas ao indivíduo e coletividade, como também a gerência da assistência à saúde em unidade básica de saúde e unidade de internação hospitalar, através da modalidade de estágio supervisionado. Nesta série ocorre a orientação para o trabalho de investigação científica (trabalho de conclusão de curso - TCC).

Neste currículo a $1^{\mathrm{a}}$ série tem como propósito da unidade educacional (UE) que o estudante compreenda e analise a organização e funcionamento da sociedade, dos serviços de saúde, do trabalho em saúde e enfermagem, a fim de assistir o indivíduo, a família e a comunidade, com vistas à promoção da saúde e prevenção de doenças.

No período de 1998 à 2001, a $1^{\text {a }}$ série desenvolveu-se através de seis unidades educacionais, a saber: UE1-Saúde e Sociedade, UE2-Trabalho em Saúde, UE3-Realidade e Saúde, UE4-Produção Social da Saúde, UE5-Urgência e Emergência Pré-hospitalar e UE6- Interação Comunitária 1.

Durante os quatro anos de implementação deste novo currículo, as capacitações, as assessorias, as reflexões, as avaliações dos docentes e discentes nos mostraram a necessidade de realizar algumas alterações referentes à estrutura e organização das unidades educacionais em todas as séries do curso. Neste trabalho nos limitamos a descrever as mudanças ocorridas na $1^{\mathrm{a}}$ série em 2002.

As unidades foram implementadas por diferentes grupos de professores, com dificuldades para que ocorresse a troca de experiências entre os mesmos e promovesse a continuidade do processo de ensino-aprendizagem.

Em 2002 houve uma fusão das quatro primeiras unidades e a UE5 foi transferida para a $2^{\mathrm{a}}$ série. Para viabilizar essa mudança foi definido um grupo de seis docentes para implementar a $1^{\text {a }}$ série, que é realizada de março a dezembro, perfazendo 967 horas, no período diurno.

Ao trabalharmos no currículo integrado as UE foram divididas, inicialmente, pelos conceitos-chave da rede explicativa que norteia o currículo do curso e pelos desempenhos. Esta rede explicativa foi construída a partir do perfil do profissional a ser formado e dos referenciais sócio-cultural, pedagógico e filosófico do PPP.

Os conceitos-chave foram trabalhados em cinco seqüências de atividades (SA), descritos a seguir:

S.A.1- Homem e Sociedade, Saúde e Doença, Modo de
Produção, Políticas de Saúde, Trabalho em Saúde e em Enfermagem.

S.A.2 - Processo de Trabalho em Saúde e em Enfermagem, Trabalho em Grupo.

S.A.3 - Modelos Assistenciais, Vigilância à Saúde, Método Epidemiológico e Saúde Ambiental.

S.A.4 - Planejamento em Saúde, Método Científico.

S.A.5 - Estrutura e dinâmica interna da Família, Método Clínico - Anamnese e Inspeção Geral.

Esses conceitos-chave são necessários para o desenvolvimento dos desempenhos estabelecidos para cada UE, ou seja, as ações que os alunos precisam construir para serem enfermeiros. Para trabalharmos com esses conceitoschave delimitados acima, contamos com a participação das seguintes áreas do conhecimento: Administração Aplicada à Enfermagem, Anatomia Humana, Bioestatística, Bioquímica, Enfermagem Clínica/Saúde Mental/Psiquiátrica/Saúde Coletiva, Epidemiologia, Ética e Bioética, Fisiologia e Biofísica, Histologia Humana, Imunologia, Informática em saúde, Microbiologia, Nutrição, Semiologia e Semiotécnica, Sociologia e Antropologia e Psicologia.

As seqüências de atividades delimitadas tiveram a intenção de desenvolver o desempenho "Presta Assistência de Enfermagem às famílias selecionadas e à comunidade empregando os métodos clínico e epidemiológico". Para isto seria necessário os demais desempenhos como:

- Analisa o trabalho em enfermagem ao longo da história;

- Compreende as formas de produzir riquezas ao longo da história;

- Identifica a corrente filosófica do pensamento e a concepção saúde e doença que sustenta os diferentes projetos de organização dos serviços de saúde de acordo com as políticas de saúde;

- Compreende o processo de produção em saúde;

- Desenvolve a investigação empregando o método científico;

- Correlaciona as estruturas familiares com a organização social no decorrer da história;

- Trabalha em grupo e

- Utiliza recursos de ensino-aprendizagem no desenvolvimento das atividades.

Os quarenta estudantes foram divididos em 6 grupos, cada qual vivenciando a realidade de uma Unidade Básica de Saúde (UBS), tendo como cenário de ensino-aprendizagem uma micro-área, sob a coordenação de um dos docentes da série. Neste mesmo ano foi proposto que os alunos da $2^{\mathrm{a}}$ série ficassem nas mesmas UBSs para que pudéssemos construir uma integração e continuidade entre as atividades das séries, podendo ter complementaridade das ações desenvolvidas na comunidade.

Utilizamos como estratégia de integração a prática do planejamento em saúde, através da aplicação da técnica do Método Altadir de Planejamento Participativo (MAPP). Dessa forma, cada grupo constituído pelos alunos da $1^{\mathrm{a}}$ e $2^{\mathrm{a}}$ séries processou um problema da micro-área em que estava inserido, tentando também contar com a participação dos profissionais do serviço e da comunidade.

As operações/ações estabelecidas no MAPP foram desenvolvidas nestas micro-áreas, sendo que os desempenhos estabelecidos foram avaliados ao longo do ano letivo.

A avaliação nas UEs é considerada como atividade permanente e dinâmica do processo de ensino-aprendizagem. Permite o acompanhamento deste processo, visualizando avanços, detectando dificuldades e, por fim realizando as intervenções necessárias, nos sujeitos deste processo, ou seja, professor, estudante e conteúdo. Portanto, a avaliação pretende acompanhar e recuperar as lacunas que este processo, eventualmente, possa conter. A avaliação refletirá o quanto o 
estudante avançou nos objetivos e desempenhos propostos na unidade, quanto o professor contribuiu para este avanço e a adequação da Unidade Educacional nesse processo( ${ }^{(6)}$.

A avaliação consiste em:

- Avaliação de desempenho - realizada pelo estudante e professor ao término de cada seqüência de atividade, através do formato 1;

- Avaliação do professor - realizada pelo estudante ao final de cada semestre, através do formato 2 e a

- Avaliação da unidade educacional - realizada pelo estudante e pelo docente ao final de cada semestre, através do formato 3.

De acordo com o Regimento da FAMEMA, o rendimento escolar é verificado em cada unidade educacional, com a atribuição de conceitos satisfatório (S) ou insatisfatório (I).

A progressão para série subseqüente ocorre mediante a obtenção do conceito satisfatório em todas as unidades educacionais da série anterior e quando o estudante não ultrapassar $25 \%$ de faltas nas unidades educacionais da série.

Se o estudante obtiver um conceito insatisfatório (I) na unidade educacional, terá direito a um plano de recuperação, que envolve uma nova avaliação. Se ainda assim mantiver o conceito I, fará uma última avaliação no período de férias próximo.

No final do ano, no mês de novembro, os alunos e docentes avaliaram a estratégia de integração e apresentaram sugestões para superação dos problemas identificados.

Os alunos da $1^{a}$ série reconhecem que a integração com a $2^{\mathrm{a}}$ série contribuiu para o desenvolvimento do seu desempenho para o planejamento em saúde, no entanto, perceberam que para os alunos da $2^{\mathrm{a}}$ série este desempenho não fazia parte de sua programação, havendo maior enfoque aos cuidados ao indivíduo.

Para os alunos da $2^{\mathrm{a}}$ série o planejamento não era um desempenho a ser desenvolvido, dificultando as atividades propostas, porém, houve contribuição para o desenvolvimento do desempenho da $1^{\text {a }}$ série, com uma visão crítica sobre a comunidade.

Por outro lado, os docentes apontam que o planejamento em saúde, através da técnica do MAPP, também não está incorporado às atividades do serviço, na medida em que houve pouca participação dos profissionais; houve também dificuldades por não ser o planejamento um desempenho proposto para a $2^{a}$ série, mesmo assim, ocorreu integração entre alguns grupos das duas séries, possibilitando uma intervenção mais efetiva.

Dentre as propostas para a superação das dificuldades encontradas na integração, os alunos e docentes apontam que deverá ter uma melhor definição dos desempenhos por série; o planejamento deverá ocorrer no início do $1^{\circ}$ semestre, para que haja maior tempo para o desenvolvimento das operações e maior contato com a comunidade; as duas séries deverão seguir uma distribuição padrão das suas atividades para facilitar os períodos de integração, bem como realizar o planejamento de ensino das unidades educacionais em conjunto; rever a distribuição da carga horária dos docentes durante a realização do mapa de atividades institucional.

\section{Referências}

1. Chaves M, Kisil M. Origens, concepção e desenvolvimento. In: Almeida M, Feuerwerker L, Llanos CM, organizadores. A educação dos profissionais de saúde na América Latina: teoria e prática de um movimento de mudança. São Paulo: Hucitec;1999.p.1-16.

2. Faculdade de Medicina de Marília. Curso de Enfermagem. Currículo do curso de enfermagem da Faculdade de Medicina de Marília. Marília (SP): Faculdade de Medicina de Marília;1997. 40p.

3. Freire P. Educação e mudança. 20ª ed. Rio de Janeiro: Paz e Terra;1994.

4. Torres Santomé J. Globalização e interdisciplinaridade: o currículo integrado. Porto Alegre (RS): Artes Médicas;1998. 275p.

5. Chirelli MQ. O processo de formação do enfermeiro crítico-reflexivo na visão dos alunos do curso de enfermagem da FAMEMA [tese Doutorado em Enfermagem]. Ribeirão Preto(SP): Escola de Enfermagem de Ribeirão Preto, Universidade de São Paulo;2002. $286 \mathrm{f}$.

6. Tonhom SFR, Otani MAP, coordenadores. Realidade, saúde e enfermagem. Marília (SP):Faculdade de Medicina de Marília; 2002.

Data de Recebimento: 11/10/2003

Data de Aprovação: 30/04/2004 